\title{
Thirty-year experience with a bileaflet mechanical valve prosthesis
}

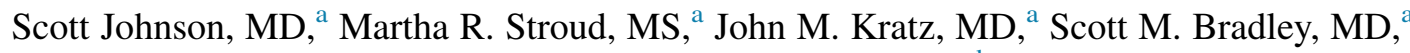

Fred A. Crawford, Jr, MD, and John S. Ikonomidis, MD, $\mathrm{PhD}^{\mathrm{b}}$

\section{ABSTRACT}

Background: The objective was to evaluate the long-term outcomes of the St Jude Medical (Saint Paul, Minn) mechanical valve prosthesis implantation.

Methods: Since 1979, every patient receiving this prosthesis has been followed annually.

Results: From January 1979 to December 2014, 1023 patients were accrued. Patients' ages ranged from 18 to 85 years. Aortic valve replacement was performed in 584 patients, and mitral valve replacement was performed in 439 patients. Follow-up was $95 \%$ complete. Operative mortality was 3\% (17/584, aortic valve replacement) and 4\% (18/439, mitral valve replacement). In patients undergoing aortic valve replacement, late actuarial survival was $62 \% \pm 2 \%, 32 \% \pm 2 \%$, and $14 \% \pm 3 \%$ at 10,20 , and 30 years, respectively. Thirty-year freedom from reoperation, thromboembolism, valve thrombosis, bleeding, and endocarditis was $92 \% \pm 2 \%, 79 \% \pm 3 \%, 96 \% \pm 1 \%, 56 \% \pm 5 \%$, and $92 \% \pm 2 \%$, respectively. In patients undergoing mitral valve replacement, late actuarial survival was $64 \% \pm 3 \%, 28 \% \pm 3 \%$, and $14 \% \pm 3 \%$ at 10,20 , and 30 years, respectively. Thirty-year freedom from reoperation, thromboembolism, valve thrombosis, bleeding, and endocarditis was $85 \% \pm 5 \%, 55 \% \pm 6 \%, 99 \% \pm 1 \%$, $57 \% \pm 6 \%$, and $95 \% \pm 2 \%$, respectively. The incidence of bleeding was $2.5 \%$ and $2.0 \%$ per patient-year for aortic valve replacement and mitral valve replacement, respectively. The incidence of thromboembolism was $1.6 \%$ and $2.9 \%$ per patient-year for aortic valve replacement and mitral valve replacement, respectively.

Conclusions: Annual follow-up of all of our patients receiving a St Jude Medical mechanical valves prosthesis has allowed better identification valve-related issues and events. After 3 decades of observation with close follow-up, the St Jude Medical mechanical valve continues to be a reliable prosthesis. (J Thorac Cardiovasc Surg 2019;157:213-22)

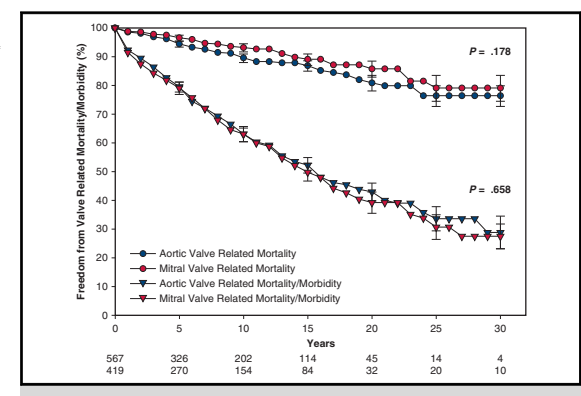

Valve-related mortality and mortality/morbidity for the St Jude Medical (Saint Paul, Minn) prosthesis.

\section{Central Message}

We evaluated the long-term outcomes of patients receiving a St Jude Medical (Saint Paul, Minn) valve prosthesis. Three decades of close follow-up indicates that this prosthesis continues to be highly reliable.

\section{Perspective}

With current advancements in bioprosthetic valves and percutaneous delivery platforms, we sought to evaluate the long-term outcomes associated with our St Jude Medical (Saint Paul, Minn) mechanical bileaflet valve registry. Three decades of observation with close follow-up indicate that the St Jude Medical mechanical valve continues to be a reliable prosthesis and is still a relevant choice for valve replacement.

See Editorial Commentary page 223.

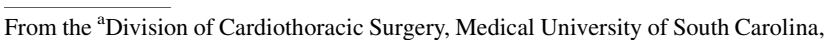
Charleston SC; and ${ }^{\mathrm{b}}$ Division of Cardiothoracic Surgery, University of North Carolina at Chapel Hill, Chapel Hill, NC.

Read at the 42nd Annual Meeting of The Western Thoracic Surgical Association, Waikoloa, Hawaii, June 22-25, 2016.

Received for publication June 21, 2016; revisions received Aug 30, 2018; accepted for publication Sept 4, 2018; available ahead of print Oct 17, 2018.

Address for reprints: John S. Ikonomidis, MD, PhD, Cardiothoracic Surgery, University of North Carolina at Chapel Hill, 3034 Burnett Womack Building, 160 Dental Circle, Chapel Hill, NC 27599-7065 (E-mail: john_ikonomidis@med.unc.edu). $0022-5223 / \$ 36.00$

Copyright (c) 2018 by The American Association for Thoracic Surgery https://doi.org/10.1016/j.jtcvs.2018.09.002
The St Jude mechanical valve (Saint Paul, Minn) is a bileaflet pyrolytic carbon valves able to be used in both mitral and aortic positions. Its low profile promised lower transvalvular gradients and decreased thrombotic events and mechanical issues compared with other mechanical valves of various design when released, which has been supported by multiple studies. ${ }^{1-10}$ Since 1979 , we have used the St Jude mechanical valve at our institution. Each patient receiving a St Jude valve at our institution has been prospectively cataloged in an ongoing database. 


\section{Abbreviations and Acronyms \\ AVR = aortic valve replacement \\ $\mathrm{CABG}=$ coronary artery bypass grafting \\ INR = international normalized ratio \\ MVR = mitral valve replacement \\ NYHA $=$ New York Heart Association \\ PVE $=$ prosthetic valve endocarditis}

This includes patients receiving a single valve, either mitral or aortic, with or without concomitant coronary artery bypass grafting (CABG). This does not include patients receiving bivalve replacement. We have previously reported on the long-term results of our patients at $4,10,15,20$, and 25 years since the first insertion. ${ }^{1,2,7,11,12}$ Through yearly surveys, we have been able to keep detailed and thorough outcome records of every patient who has received a St Jude valve at our institution. We present our 30-year data.

\section{MATERIALS AND METHODS}

Between January of 1979 and December of 2014, all patients undergoing valve replacement were prospectively entered into a computer database. Yearly questionnaires were mailed to all patients. If the questionnaires were not returned or the patient reported an adverse event, telephone or personal interviews were conducted. The Social Security Death Index was used to confirm the date of any patient who died during the follow-up period. A total of 56 patients were lost to follow-up (36 aortic valve replacements [AVRs], 20 mitral valve replacements [MVRs]); therefore, follow-up was $95 \%$ complete, including 6174 total years for the aortic cohort and 4735 total years for the mitral cohort. This study was approved by the Institutional Review Board of the Medical University of South Carolina, and individual consent was waived. Morbidity and mortality were stringently defined according to the guidelines of the Society of Thoracic Surgeons and the American Association for Thoracic Surgery. ${ }^{13,14}$ Demographics are shown in Table 1.

Operative techniques were similar to those previously reported. Throughout the study, changes in operative strategy included a tendency toward retrograde perfusion later in the study, as well as sparing the subvalvular apparatus in the mitral position, whenever possible, starting in 1988. Valves were placed with everting sutures through the annulus, allowing for an intra-annular position of the valve. Sizes for the 2 groups ranged from $19 \mathrm{~mm}$ to $33 \mathrm{~mm}$. A silver impregnated ring was used during 1999, but the ring was discontinued at our institution because of increased paraprosthetic leak rates.

With regard to anticoagulation, 5000 units of subcutaneous heparin was started on the first postoperative day and was continued until the prothrombin time or, more recently, the international normalized ratio (INR) was regulated with the administration of warfarin sodium. If the INR was not therapeutic by postoperative day 5, patients would be bridged with a heparin drip until they became therapeutic on oral anticoagulation. Early in our experience, the INR was maintained at 2.5 to 3.5. More recently, we have recommended an INR of 2 for patients who have undergone AVR and 2.0 to 2.5 for MVR; however, Coumadin dosing and INR level were managed by the patient's primary care physician or cardiologist, not the surgeon. Patients were not discharged until their INR was therapeutic. Unless a CABG was
TABLE 1. Patient demographics

\begin{tabular}{|c|c|c|}
\hline Variable & AVR & MVR \\
\hline Total number & 584 & 439 \\
\hline \multicolumn{3}{|l|}{ Age (y) } \\
\hline Range & $18-83$ & $18-85$ \\
\hline Mean \pm SD & $55 \pm 14$ & $53 \pm 13$ \\
\hline \multicolumn{3}{|l|}{ Sex } \\
\hline Male & $411(70 \%)$ & $179(41 \%)$ \\
\hline Female & $173(30 \%)$ & $260(59 \%)$ \\
\hline \multicolumn{3}{|l|}{ Etiology } \\
\hline Rheumatic & $75(13 \%)$ & $176(40 \%)$ \\
\hline Native valve endocarditis & $41(7 \%)$ & $31(7 \%)$ \\
\hline Degenerative/calcific & $271(46 \%)$ & $119(27 \%)$ \\
\hline Bicuspid aortic valve & $113(19 \%)$ & - \\
\hline Other congenital & $36(6 \%)$ & $7(2 \%)$ \\
\hline Ischemic & - & $39(9 \%)$ \\
\hline Reoperative & $45(8 \%)$ & $64(14 \%)$ \\
\hline Other & $3(.5 \%)$ & $3(1 \%)$ \\
\hline \multicolumn{3}{|l|}{ Lesion } \\
\hline Stenosis & $323(55 \%)$ & $104(24 \%)$ \\
\hline Insufficiency & $188(32 \%)$ & $271(62 \%)$ \\
\hline Mixed & $73(13 \%)$ & $64(15 \%)$ \\
\hline \multicolumn{3}{|l|}{ Valve sizes $(\mathrm{mm})$} \\
\hline 19 & $88(15 \%)$ & - \\
\hline 21 & $149(26 \%)$ & $1(.2 \%)$ \\
\hline 23 & $171(29 \%)$ & $3(1 \%)$ \\
\hline 25 & $103(18 \%)$ & $8(2 \%)$ \\
\hline 27 & $55(9 \%)$ & $62(14 \%)$ \\
\hline 29 & $11(2 \%)$ & $157(36 \%)$ \\
\hline 31 & $6(1 \%)$ & $125(29 \%)$ \\
\hline 33 & $1(0.2 \%)$ & $83(19 \%)$ \\
\hline Associated CABG & $179(31 \%)$ & $82(19 \%)$ \\
\hline \multicolumn{3}{|l|}{ Preoperative NYHA class } \\
\hline I & $26(4 \%)$ & $14(3 \%)$ \\
\hline II & $108(18 \%)$ & $36(8 \%)$ \\
\hline III & $297(51 \%)$ & $215(49 \%)$ \\
\hline IV & $153(26 \%)$ & $174(40 \%)$ \\
\hline Operative mortality & $17(3 \%)$ & $20(5 \%)$ \\
\hline Average follow-up (y) & $11 \pm 8$ & $11 \pm 8$ \\
\hline Lost to follow-up & $36(6 \%)$ & $20(5 \%)$ \\
\hline
\end{tabular}

$\overline{A V R}$, Aortic valve replacement; $M V R$, mitral valve replacement; $S D$, standard deviation; $C A B G$, coronary artery bypass graft; NYHA, New York Heart Association.

performed concurrent with our valve therapy, we did not routinely prescribe antiplatelet therapy upon discharge.

\section{Statistical Analysis}

Continuous variables are reported as mean \pm 1 standard deviation, and categoric variables are represented as percentages. Actuarial curves were constructed to describe mortality, and the incidence of valve-related complications using the Kaplan-Meier technique are reported with the standard error of the mean. ${ }^{15-17}$ Because actuarial analysis is known to overestimate the incidence of nonfatal end points, cumulative incidence curves were constructed for both the AVR and MVR groups for the end points of reoperation, endocarditis, thromboembolic events, and 


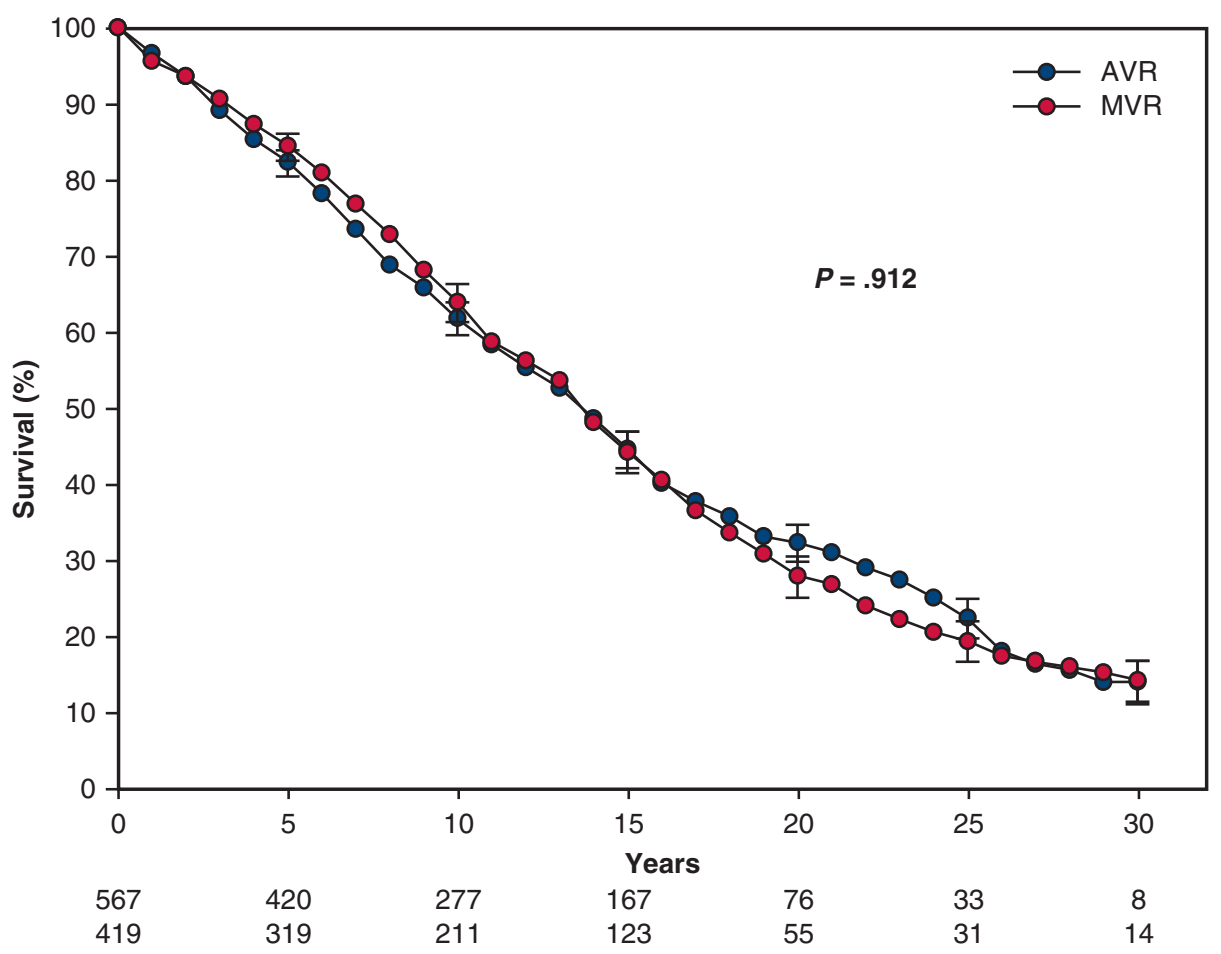

FIGURE 1. Actuarial survival after AVR and MVR. $A V R$, Aortic valve replacement; $M V R$, mitral valve replacement.

anticoagulation-related hemorrhage. ${ }^{18}$ Linearized rates, used to describe multiple events, were reported as \%/patient year. Independent factors associated with operative and late death were identified using logistic regression ${ }^{19}$ and Cox proportional hazards regression model, ${ }^{20}$ respectively. Variables used for both the AVR and MVR groups are summarized in the Appendix. Effective orifice areas used for analysis were provided by St Jude Medical, Inc.

\section{RESULTS}

The total number of patients surveyed was 1023 , from January 1979 to December 2014. Ages ranged from 18 to 85 years. Ninety-five percent of the patients had complete follow-up. Male patients represented 70\% (411/584) of the aortic valve recipients and $41 \%(179 / 439)$ of the mitral valve recipients. Seventy-seven percent (450/584) of the aortic valve recipients and $89 \%(389 / 439)$ of the mitral valve recipients were in New York Heart Association (NYHA) class III or IV. Nineteen- and 21-mm valves accounted for $41 \%$ (238/584) of aortic implants. Concomitant coronary artery bypass was carried out in $31 \%(179 / 584)$ of aortic valve recipients and 19\% (82/439) of mitral valve recipients (Table 1).

\section{Survival}

Operative mortality was 3\% (17/584) in the aortic valve recipients. Logistic regression analysis showed that concomitant $\mathrm{CABG}$ of 3 or more vessels $(P=.019)$, size 19 valve $(P=.029)$, and NYHA Class IV $(P=.038)$ were independent predictors of operative death in the
AVR cohort, and native valve endocarditis approached significance $(P=.054)$.

Among aortic valve recipients, late actuarial survival was $82 \% \pm 2 \%, 62 \% \pm 2 \%, 45 \% \pm 2 \%, 32 \% \pm 2 \%$, $22 \% \pm 3 \%$, and $14 \% \pm 3 \%$ at $5,10,15,20,25$, and 30 years, respectively (Figure 1). Cox Regression analysis identified older age at operation $(P<.0005)$, concomitant CABG $(P<.0005)$, and preoperative NYHA Class III or IV $(P=.003)$ as independent predictors of late death. Effective orifice area index less than 0.8 approached significance $(P=.055$, Tables 2 and 3$)$

The mitral valve cohort experienced operative mortality of $5 \%(20 / 439)$. Increased age at operation $(P=.012)$ and NYHA Class IV $(P=.004)$ were identified as predictors of operative death.

In the MVR cohort, late actuarial survival was $84 \% \pm 2 \%, 64 \% \pm 3 \%, 44 \% \pm 3 \%, 28 \% \pm 3 \%$, $19 \% \pm 3 \%$, and $14 \% \pm 3 \%$ at $5,10,15,20,25$, and 30 years, respectively (Figure 1$)$. Older age $(P<.0005)$, ischemic etiology $(P=.011)$, and preoperative NYHA Class IV $(P=.014)$ were found to be predictors for late death (Tables 2 and 3).

\section{Reoperation}

Reoperation occurred in 34 patients in the AVR group and 24 patients in the MVR group. Reasons for reoperation in the AVR group were prosthetic valve endocarditis (PVE) 
TABLE 2. Univariate associations with operative and late death

\begin{tabular}{lc}
\hline \multicolumn{1}{c}{ Variable } & $\boldsymbol{P}$ value \\
\hline Operative death & \\
AVR & .008 \\
Valve size 19 & .021 \\
Preoperative NYHA class IV & .066 \\
CABG $\geq 3$ vessels & .110 \\
Native valve endocarditis & \\
MVR & .002 \\
Preoperative NYHA class IV & .004 \\
Older age & .009 \\
CABG $\geq 3$ vessels & .182 \\
Lesion MR & \\
Late death & $<.0005$ \\
AVR & $<.0005$ \\
Older age & $<.0005$ \\
Lesion AS & $<.0005$ \\
Associated CABG & $<.0005$ \\
Preoperative NYHA class III/IV & .027 \\
Decreased EOAI & \\
Valve size 19 & $<.0005$ \\
MVR & $<.0005$ \\
Older age & $<.0005$ \\
Associated CABG & .024 \\
Ischemic etiology & .027 \\
Lesion MR & \\
Preoperative NYHA class IV & \\
\hline
\end{tabular}

$A V R$, Aortic valve replacement; $N Y H A$, new York Heart Association; $C A B G$, coronary artery bypass graft; $M V R$, mitral valve replacement; $M R$, mitral regurgitation; $A S$, aortic stenosis; EOAI, estimated orifice area index.

in 19 patients ( 3 fatal), perivalvar dehiscence in 6 patients, and other causes in 9 patients ( 1 fatal). Indications for reoperation in the MVR group were PVE in 10 patients, perivalvar dehiscence in 11 patients, and other reasons in 3 patients (1 fatal). There was no incidence of structural valve deterioration observed in either group. In the AVR group, 30-year actuarial freedom from reoperation was $92 \% \pm 2 \%$ and cumulative 30-year freedom from reoperation was $94 \% \pm 1 \%$. In the MVR group, the 30-year actuarial freedom from reoperation was $85 \% \pm 5 \%$, and cumulative 30 -year freedom from reoperation was $93 \% \pm 1 \%$. The AVR incidence rate for reoperation was $0.6 \% /$ patientyear. The MVR incidence rate for reoperation was $0.5 \%$ / patient-year (Figure 2).

\section{Thromboembolism}

In the AVR group, thromboembolism occurred in $80 \mathrm{pa}-$ tients (103 events). Fifty-six were defined as strokes (14 fatal). Twenty-nine were defined as transient ischemic attacks. There were 5 peripheral embolic events ( 2 fatal) and 13 incidents ( 4 fatal) of valve thrombosis. This results in an incident rate of 1.7\%/patient-year. In the MVR group, thromboembolism occurred in 95 patients (135 events). Seventy-three were defined as strokes (14 fatal). Fifty-two
TABLE 3. Multivariable associations with operative and late death

\begin{tabular}{|c|c|c|c|}
\hline & $P$ value & OR & $95 \%$ confidence limit \\
\hline \multicolumn{4}{|l|}{ Operative death } \\
\hline \multicolumn{4}{|l|}{ AVR } \\
\hline CABG $\geq 3$ vessels & .019 & 4.4 & $1.27-15.41$ \\
\hline Size 19 valve & .003 & 4.8 & $1.68-13.75$ \\
\hline \multicolumn{3}{|l|}{ Class IV } & $1.06-7.94$ \\
\hline Endocarditis & .054 & 4.0 & $0.98-16.16$ \\
\hline Older age & .012 & 1.06 & $1.01-1.10$ \\
\hline \multicolumn{4}{|l|}{ Class IV } \\
\hline \multicolumn{4}{|l|}{ Late death } \\
\hline \multicolumn{4}{|l|}{ AVR } \\
\hline Older age & $<.0005$ & 1.04 & $1.03-1.05$ \\
\hline Associated CABG & $<.0005$ & 1.67 & $1.32-2.10$ \\
\hline $\begin{array}{l}\text { Preoperative NYHA } \\
\text { III/IV }\end{array}$ & .003 & 1.52 & $1.16-1.99$ \\
\hline EOAI $<0.8$ & .055 & 1.26 & $0.99-1.60$ \\
\hline \multicolumn{4}{|l|}{ MVR } \\
\hline Older age & $<.0005$ & 1.04 & $1.03-1.05$ \\
\hline Ischemic etiology & .011 & 1.65 & $1.12-2.43$ \\
\hline Preoperative NYHA IV & .014 & 1.37 & $1.07-1.76$ \\
\hline
\end{tabular}

$\overline{A V R}$, Aortic valve replacement; $C A B G$, coronary artery bypass graft; $N Y H A$, New York Heart Association; EOAI, estimated orifice area index; $M V R$, mitral valve replacement.

were defined as transient ischemic attacks. There were 6 peripheral embolic events and 4 incidents of valve thrombosis. This results in an incident rate of 2.9\%/patient-year. Kaplan-Meier 30-year freedom from thromboembolism was $79 \% \pm 3 \%$ in the AVR group and $56 \% \pm 6 \%$ in the MVR group. Cumulative 30-year freedom from thromboembolism was $85 \% \pm 2 \%$ in the AVR group and $73 \% \pm 3 \%$ in the MVR group (Figure 3).

\section{Valve Thrombosis}

In the AVR group, valve thrombosis occurred in 13 patients (13 events). In the MVR group, valve thrombosis occurred in 4 patients (4 events). Kaplan-Meier 30-year freedom from thromboembolism was $76 \% \pm 3 \%$ in the AVR group and $54 \% \pm 6 \%$ in the MVR group. Cumulative 30 -year freedom from thromboembolism was $83 \% \pm 2 \%$ in the AVR group and $73 \% \pm 3 \%$ in the MVR group (Figure 4).

\section{Bleeding}

In the AVR group, there were 149 events (126 patients) of bleeding requiring hospitalization or transfusion. There were 75 (1 fatal) incidents of gastrointestinal bleeding, 39 (29 fatal) of cerebral bleeding, 4 ( 2 fatal) of cardiac tamponade, 12 of internal bleeding, 9 of epistaxis, 5 of hematoma, 2 of hematuria, 2 of retinal bleeding, and 1 of vaginal bleeding. This results in an incident rate of $2.4 \%$ /patientyear. In the MVR group, there were 95 events (78 patients) 


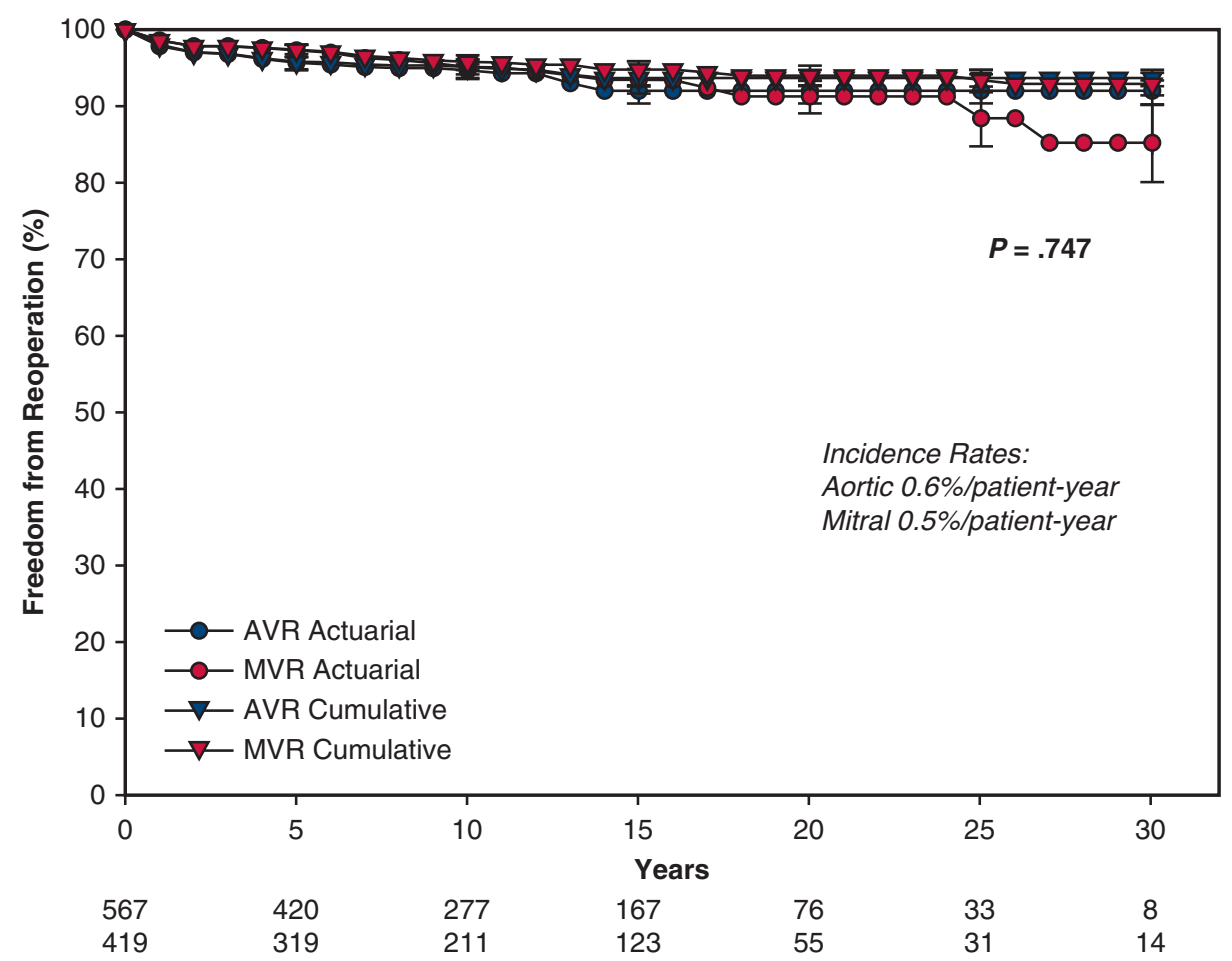

FIGURE 2. Actuarial and "actual" freedom from reoperation after AVR and MVR. AVR, Aortic valve replacement; $M V R$, mitral valve replacement.

of bleeding requiring hospitalization or transfusion. There were 49 (4 fatal) incidents of gastrointestinal bleeding, 21 (14 fatal) of cerebral bleeding, 4 ( 1 fatal) of cardiac tamponade, 9 (1 fatal) of internal bleeding, 3 of epistaxis, 3 of hematoma, 1 of hematuria, 2 of retinal bleeding, and 3 of vaginal bleeding. This results in an incident rate of $2.0 \% /$ patient-year.

Actuarial freedom from bleeding in the AVR group at 30 years was $56 \% \pm 5 \%$. Actuarial freedom from bleeding in the MVR group at 30 years was $57 \% \pm 6 \%$. Cumulative freedom from bleeding was $72 \% \pm 2 \%$ in the AVR group and $76 \% \pm 2 \%$ in the MVR group. The incidence rate was $2.4 \%$ patient-year in the AVR group and $2.0 \%$ /patient-year for the MVR group (Figure 5).

\section{Endocarditis}

A total of 30 ( 7 fatal) patients in the AVR group and 13 (2 fatal) patients in the MVR group experienced PVE. This results in an incident rate of $0.5 \%$ /patient-year in the AVR group and $0.3 \%$ /patient-year in the MVR group. Actuarial freedom from PVE at 30 years was $92 \% \pm 2 \%$ in the AVR group and $95 \% \pm 2 \%$ in the MVR group. Cumulative freedom from PVE at 30 years was $94 \% \pm 2 \%$ for the AVR group and $97 \% \pm 1 \%$ for the MVR group (Figure 6).

\section{Valve-Related Mortality}

A total of 63 patients in the AVR group had a valverelated mortality. Causes of mortality include embolism
(14), valve thrombosis (4), bleeding (32), endocarditis (7), reoperative death (4), death at a subsequent catheterization (1), and peripheral emboli (2). A total of 37 patients in the MVR group had a valve-related mortality. Causes of mortality included embolism (14), bleeding (20), endocarditis (2), and reoperative death (1). Kaplan-Meier analysis shows 30year freedom from valve-related mortality to be $76 \% \pm 4 \%$ in the AVR group and $79 \% \pm 5 \%$ in the MVR group (Figure 6). The cause of death was unknown for 61 of the patients who underwent AVR and 50 of the patients who underwent MVR.

\section{Valve-Related Morbidity and Mortality}

A total of 226 patients experienced valve-related morbidity and mortality in the AVR group. A total of 181 patients experienced valve-related morbidity and mortality in the MVR group. Kaplan-Meier analysis shows 30-year freedom from valve-related morbidity and mortality to be $29 \% \pm 6 \%$ in the AVR group and $27 \% \pm 4 \%$ in the MVR group (Figure 7).

\section{DISCUSSION}

The St Jude bioprosthetic valve was introduced in 1977 as an alternative to tilting disk and caged ball valve prosthesis. It was approved by the Food and Drug Administration in 1982 for public use. Both in vitro and in vivo studies demonstrate low gradients across the valve in both catheterization and echocardiographic evaluations, ${ }^{15,16}$ 


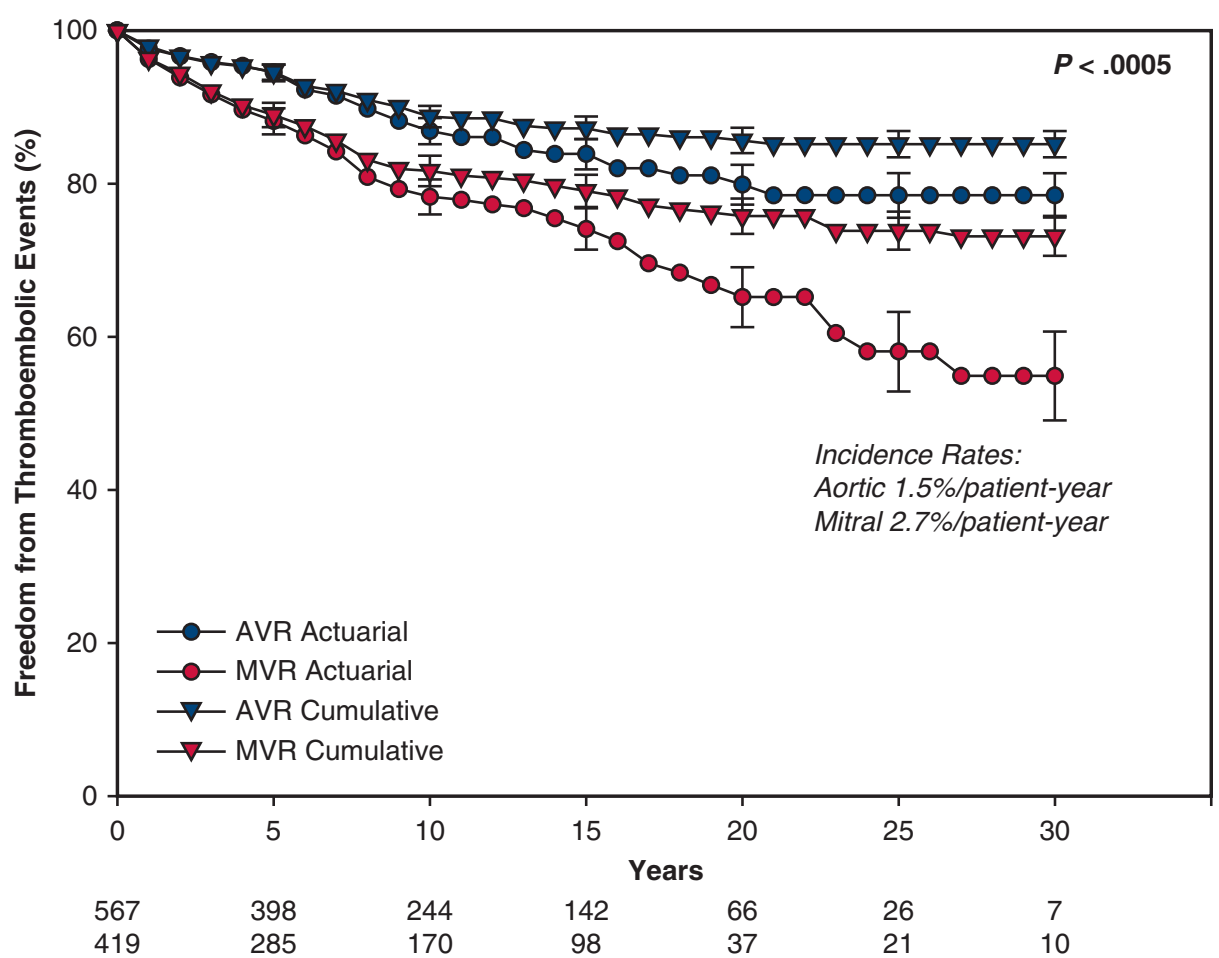

FIGURE 3. Actuarial and "actual" freedom from thromboembolic events after AVR and MVR. AVR, Aortic valve replacement; $M V R$, mitral valve replacement.

which were the main reasons we chose to use this valve early in its investigative period. Through multiple studies, we continue to observe the excellent durability of the
St Jude mechanical prosthesis. ${ }^{1,2,7-11}$ In addition to durability, we continue to report low incidences of thromboembolism. We hope that annual prospective

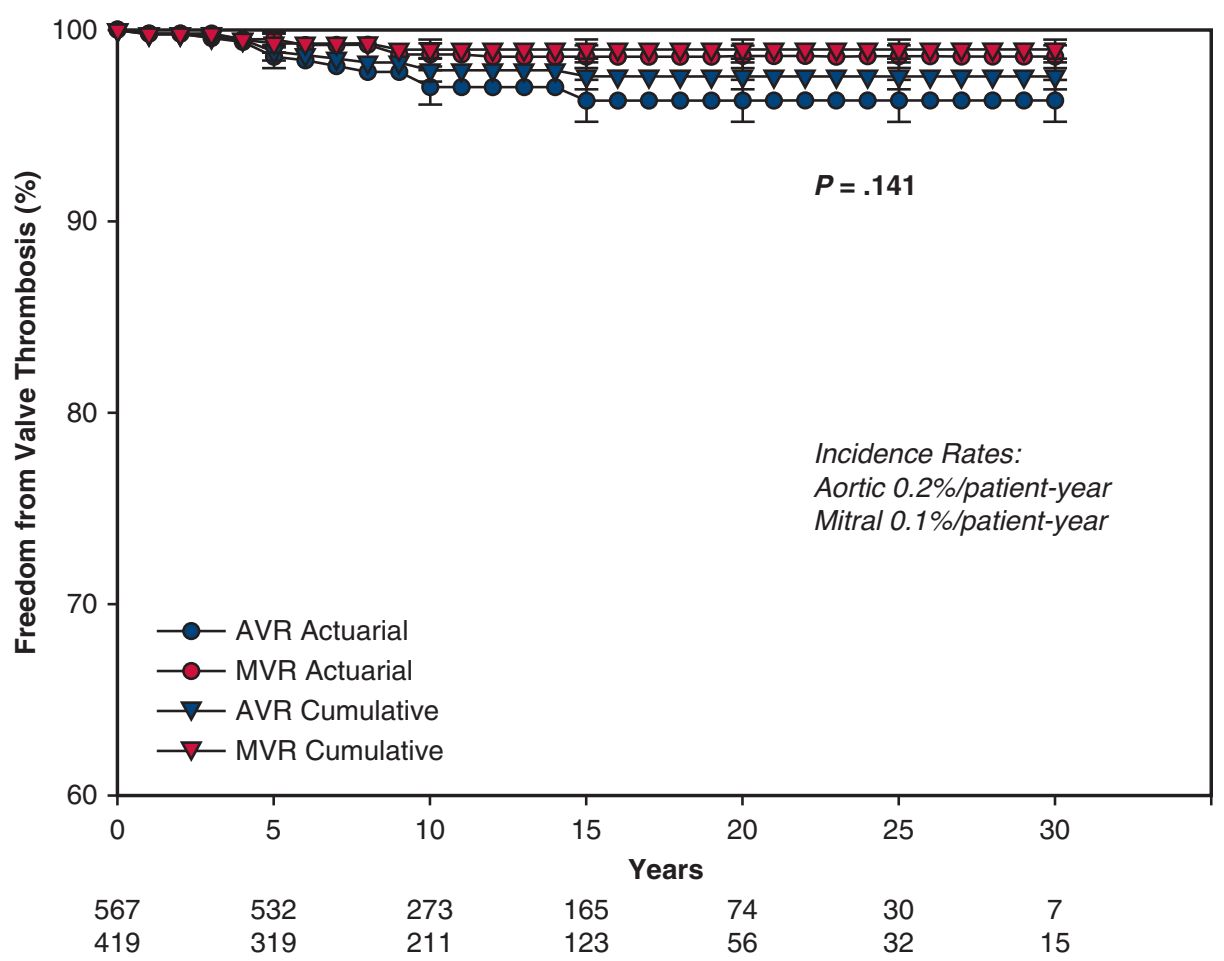

FIGURE 4. Actuarial and "actual" freedom from valve thrombosis after AVR and MVR. AVR, Aortic valve replacement; $M V R$, mitral valve replacement. 


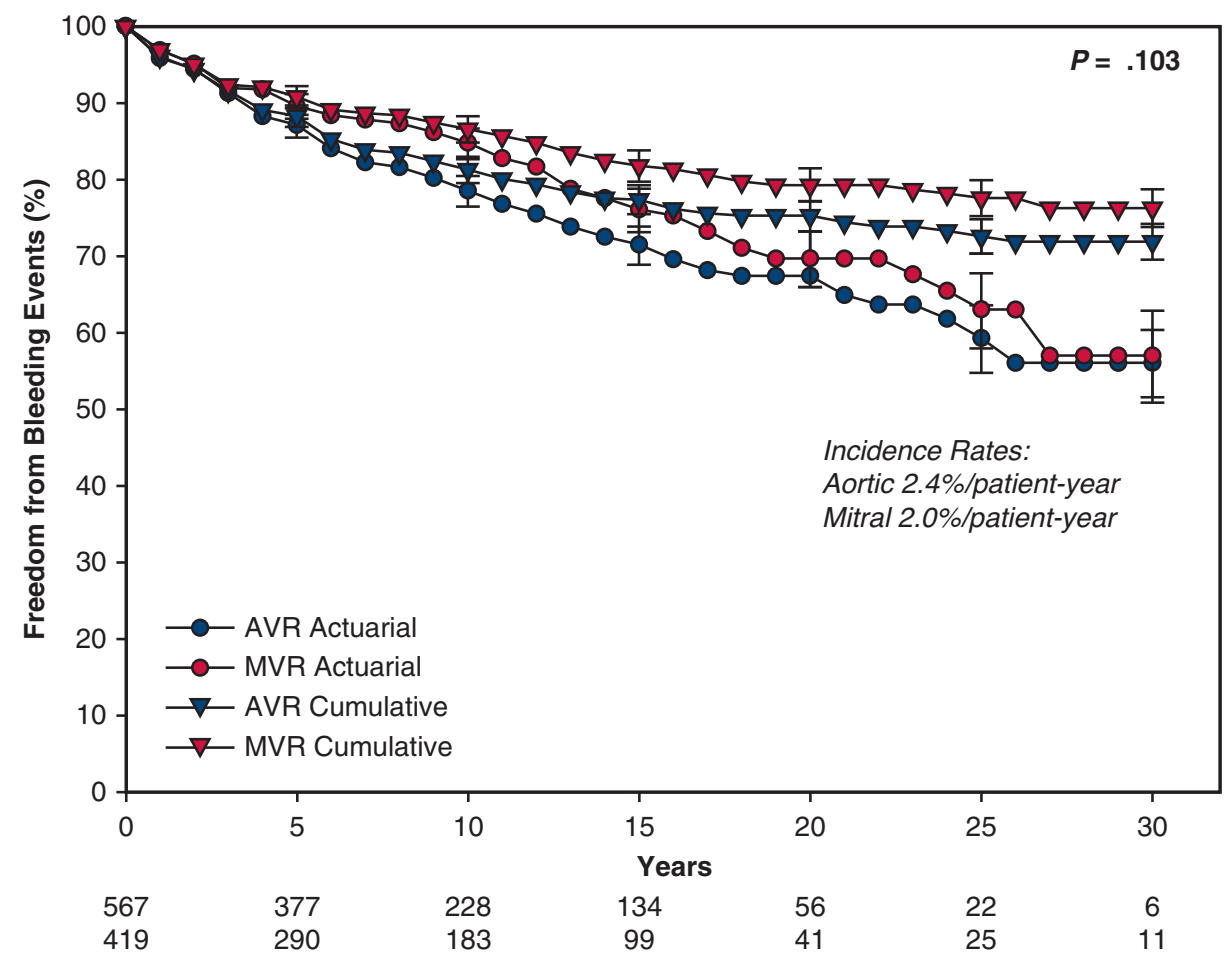

FIGURE 5. Actuarial and "actual" freedom from bleeding events after AVR and MVR. $A V R$, Aortic valve replacement; $M V R$, mitral valve replacement.

follow-up of all patients in our cohort allows for more accurate reporting because of a shorter recall time for our patients as it relates to different events.
As we have reported before, our operative mortality $(3 \%$ and 5\% for AVR and MVR, respectively) is comparable to other long-term studies on prostheses. ${ }^{8-10,17-20}$ In this series,

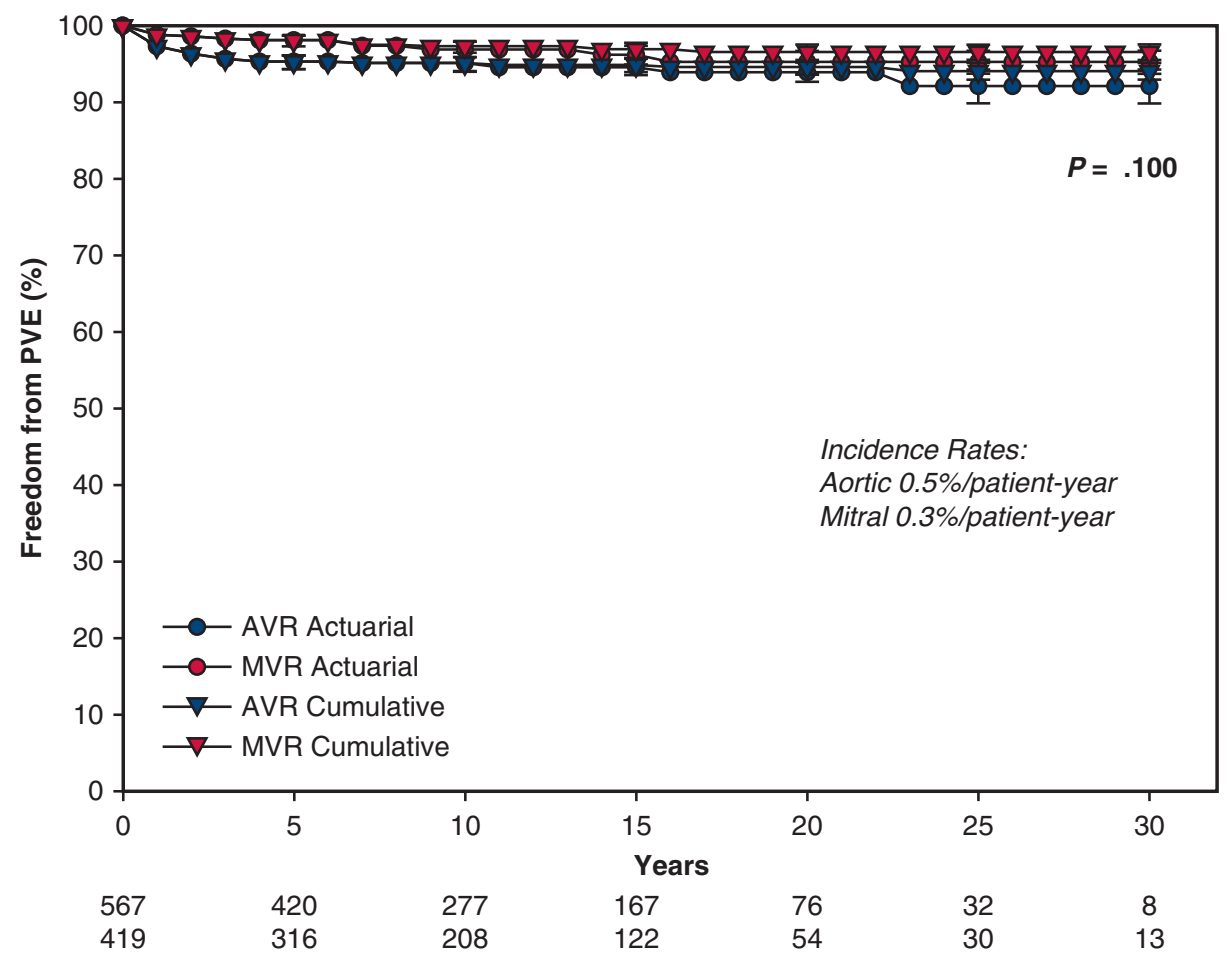

FIGURE 6. Actuarial and "actual" freedom from PVE after AVR and MVR. PVE, Prosthetic valve endocarditis; $A V R$, aortic valve replacement; $M V R$, mitral valve replacement. 


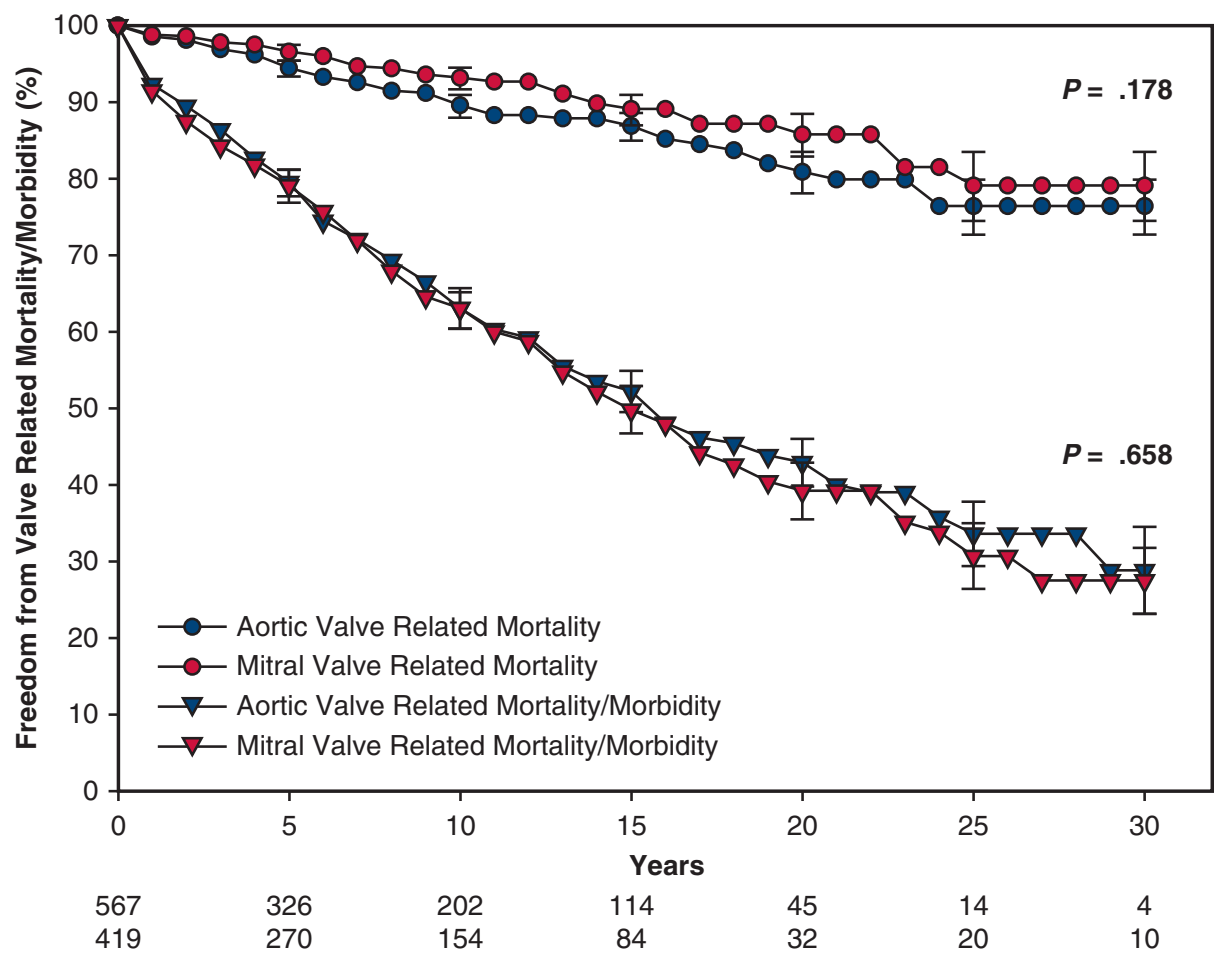

FIGURE 7. Actuarial and "actual" freedom from valve-related morbidity or mortality after AVR and MVR.

unlike previous series, we do not see effective orifice area index as a predictor of operative death in patients undergoing AVR. ${ }^{1,2,7,11,12}$ However, it did approach significance as a predictor of late death. In addition, we continue to see a large discrepancy between overall mortality and valve-related mortality. We believe this once again shows that mortality is more closely related to patient characteristics and not to valve-specific issues or concerns.

Thromboembolism and bleeding continue to be the major concern with respect to mechanical prosthetic valves. We found linearized rates of thromboembolism and bleeding in the AVR group to be $1.7 \%$ /patient year and $2.4 \% /$ patient year, respectively. In the mitral group, these rates were $2.9 \%$ /patient year and $2.0 \%$ patient year, respectively. When compared with our previous reports, these linearized rates continue to decrease. ${ }^{1,2,7,11,12}$ Also of note, $40 \%$ of these thromboembolic events can be categorized as minor events. On the basis of these results, we have continued to recommend target INRs of 2 for AVR and 2 to 2.5 for MVR. This has been recommended by other groups as well ${ }^{21-23}$; however, these recommendations are less than the 2014 American College of Cardiology guidelines for both AVR and MVR. ${ }^{24}$ Some authors even argue for lower INR goals for certain patients undergoing AVR. ${ }^{25}$

The incidence of PVE continues to be low. Endocarditis accounted for $9 \%$ of our valve-related mortality deaths. As previously reported, the majority of these cases of endocarditis occurred early in the study and have been low in number since. ${ }^{1,2,7,11,12}$ Currently, linearized rates of PVE are $0.5 \% /$ patient-year and $0.6 \%$ /patient-year for AVR and MVR, respectively.

Mechanical valve insertion continues to decrease over time. From 2005 to 2014, mechanical valves account for $12 \%$ of our overall valve replacement at our institution. This compares with 1980 to 1989, when mechanical valves accounted for $61 \%$ of our overall valve replacement. Others have also reported a similar trend. ${ }^{26,27}$ This is most likely multifactorial, secondary to younger patients choosing tissue valves because of increased durability in new models, better postoperative care, no need for lifelong anticoagulation, and the possibility of future valve-in-valve procedures with transcatheter aortic valve replacements continuing to have a larger footprint in valve disease. That being said, we believe there continues to be a need for MVR. We must continue to weigh the risks of bleeding mortality with reoperation mortality to best serve our patients. Our current guidelines recommend considering mechanical valves before ages 60 to 65 years because of their durability. ${ }^{24}$ However, this is based on a life expectancy of approximately 80 years, which continues to increase with each generation. As we have seen in our cohort, the St Jude mechanical valve continues to be highly durable and reliable, with a low reoperation rate. In addition, as we continue to learn more 
about novel anticoagulation, we will hopefully move away from continuous laboratory monitoring toward singledose, easily reversible anticoagulation. Home monitoring continues to be developed. As this becomes a real option, this will also make monitoring anticoagulation easier and more reliable. Finally, new valves are continuing to be developed that require lower anticoagulation goals. ${ }^{28,29}$ With these developments, mechanical valve insertion continues to be a safe, viable option for select patients.

\section{Study Limitations}

Our study does have some limitations. Because the data reported are generated from a yearly questionnaire and patients are not followed in our clinic, we are limited by the information in our dataset that is provided by the patients themselves. Although we recommend certain INR goals for patients, their home cardiologist or family medicine doctor may alter their goal as they see fit, affecting our results. Despite our close follow-up, there were some patients for whom we were unable to elucidate the cause of death. If patients were noted to die suddenly, they were counted as a valve-related mortality; however, for some patients, death certificates could not be obtained, leaving the involvement of their valve in their death unknown. Finally, because of the nature of our follow-up, the circumstances of some of the adverse events were unable to be adequately elucidated. With that stated, we believe our close yearly follow-up, including phone follow-up for any reported adverse events, minimized our limitations within reason.

\section{CONCLUSIONS}

The St Jude mechanical valve remains highly reliable. We observed no structural failures in more than 30 years of follow-up, and reoperation was rare. We have found mortality is more often due to age, cardiac function, and coronary artery disease as opposed to valve-related factors. Because of these attributes, the St Jude Medical mechanical valve remains our mechanical valve of choice.

\section{Conflict of Interest Statement}

Authors have nothing to disclose with regard to commercial support.

\section{References}

1. Crawford FA Jr, Kratz JM, Sade RM, Stroud MR, Bartles DM. Aortic and mitral valve replacement with the St. Jude medical prosthesis. Ann Surg. 1984;199: 753-61.

2. Kratz JM, Crawford FA Jr, Sade RM, Crumbley AJ III, Stroud MR. St Jude prosthesis for aortic and mitral valve replacement: a ten year experience. Ann Thorac Surg. 1993;56:462-8.

3. Arom KV, Nicoloff DM, Kersten TE, Lindsay WG, Northrup WF III. St Jude medical prosthesis: valve-related deaths and complications. Ann Thorac Surg. 1987;43:591-8
4. Arom KV, Nicoloff DM, Kersten TE, Northrup WF III, Lindsay WG, Emery RW Ten years' experience with the St Jude medical valve prosthesis. Ann Thorac Surg. 1989; 47:831-7.

5. Czer LS, Chaux A, Matloff JM, DeRobertis MA, Nessim SA, Scarlata D, et al Ten-year experience with the St. Jude medical valve for primary valve replacement. J Thorac Cardiovasc Surg. 1990;100:44-55.

6. Khan S, Chaux A, Matloff J, Blanche C, DeRobertis M, Kass R, et al. The St. Jude medical valve. Experience with 1000 cases. J Thorac Cardiovasc Surg. 1994; 108:1010-20.

7. Zellner JL, Kratz JM, Crumbley AJ III, Stroud MR, Bradley SM, Sade RM, et al. Long-term experience with the St. Jude medical valve prosthesis. Ann Thorac Surg. 1999;68:1210-8.

8. Remadi JP, Baron O, Roussel C, Bizouarn P, Habasch A, Despins P, et al. Isolated mitral valve replacement with St. Jude medical prosthesis: long-term results: a follow-up of 19 years. Circulation. 2001;103:1542-5.

9. Lund O, Nielsen SL, Arildsen H, Ilkjaer LB, Pilegaard HK. Standard aortic St. Jude valve at 18 years: performance profile and determinants of outcome. Ann Thorac Surg. 2000;69:1459-65.

10. Emery RW, Arom KV, Kshettry VR, Kroshus TJ, Von R, Kersten TE, et al. Decision-making in the choice of heart valve for replacement in patients aged 60-70 years: twenty-year follow up of the St. Jude medical aortic valve prosthesis. $J$ Heart Valve Dis. 2002;11(Suppl 1):S37-44.

11. Ikonomidis JS, Kratz JM, Crumbley AJ III, Stroud MR, Bradley SM, Sade RM et al. Twenty year experience with the St. Jude medical mechanical valve prosthesis. J Thorac Cardiovasc Surg. 2003;126:2022-31.

12. Toole JM, Stroud MR, Kratz JM, Crumbley AJ III, Bradley SM Crawford FA Jr, et al. Twenty-five year experience with the St. Jude medical mechanical valve prosthesis. Ann Thorac Surg. 2010;89:1402-9.

13. Edmunds LH, Clarke RE, Cohn LH, Miller DC, Weisel RD. Guidelines for reporting morbidity and mortality after cardiac operations. Ann Thorac Surg. 1996;62:932-5.

14. Akins CW, Miller DC, Turina MI, Kouchoukos NT, Blackstone EH, Grunkemeier GL, et al. Guidelines for reporting mortality and morbidity after cardiac valve interventions. J Thorac Cardiovasc Surg. 2008;135:732-8.

15. Emery RW, Krogh CC, Arom KV, Emery AM, Benyo-Albrecht K, Joyce LD, et al. The St. Jude medical cardiac valve prosthesis: a 25-year experience with single valve replacement. Ann Thorac Surg. 2005;79:776-82.

16. Gray RJ, Chaux A, Matloff JM, DeRobertis M, Raymond M, Stewart M et al. Bileaflet, tilting disc and porcine valve substitutes: in vivo hydrody namic characteristics. J Am Coll Cardiol. 1984;3:321-7.

17. Khan SS, Trento A, DeRobertis M, Kass RM, Sandhu M, Czer LS, et al Twenty year comparison of tissue and mechanical valve replacement. $J$ Thorac Cardiovasc Surg. 2001;122:257-69.

18. Masters RG, Helou J, Pipe AL, Keon WJ. Comparative clinical outcomes with St. Jude medical, Medtronic hall and Carbomedics mechanical heart valves. J Heart Valve Dis. 2001;10:403-9.

19. Butchart EG, Li HH, Payne N, Buchan K, Grunkenmeier GL. Twenty years experience with the Medtronic hall valve. J Thorac Cardiovasc Surg. 2001;121: 1090-100.

20. Anttila V, Heikkinen J, Biancari F, Oikari K, Pokela R, Lepojärvi M, et al. A retrospective comparative study of aortic valve replacement with St. Jude Medical and Medtronic hall prostheses: a 20 year follow up study. Scand Cardiovasc J. 2002;36:53-9.

21. Arom KV, Emery RW, Nicoloff DM, Petersen RJ. Anticoagulation related complications in elderly patients with St. Jude mechanical valve prosthesis. J Heart Valve Dis. 1996:5:505-10.

22. Horstkotte D, Schulte HD, Bircks W, Strauer BE. Lower intensity anticoagulation therapy results in lower complication rates with the St. Jude medical prosthesis. J Thorac Cardiovasc Surg. 1994;107:1136-45.

23. Hering D, Piper C, Bergemann R, Hillenbach C, Dahm M, Huth C, et al. Thromboembolic and bleeding complications following St. Jude following St. Jude medical valve replacement: results of the German experience with low intensity anticoagulation study. Chest. 2005; 127:53-9.

24. Nishimura RA, Otto CM, Bonow RO, Carabello BA, Erwin JP III, Guyton RA, et al. 2014 AHA/ACC guideline for the management of patients with valvular heart disease: executive summary: a report of the American College of Cardiology/American Heart Association task force on practice guidelines. Circulation. 2014;129:2440-92.

25. Emery RW, Emery AM, Raikar GV, Shake JG. Anticoagulation for mechanical heart valves: a role for patient based therapy. J Thromb Thrombolysis. 2007; 25:18-25. 
26. Brown J, O'Brien S, Wu C, Sihora J, Griffith B, Gammie J. Isolated aortic valve replacement in North America comprising 108,687 patients in 10 years: changes in risk, valve types and outcomes in the Society of Thoracic Surgeon database. $J$ Thorac Cardiovasc Surg. 2009;137:82-90.

27. Gammie JS, Sheng S, Griffith BP, Peterson ED, Rankin JS, O’Brien SM, et al. Trends in mitral valve surgery in the United States: results from the Society of Thoracic Surgeons adult cardiac surgery database. Ann Thorac Surg. 2009;87:1431-7.

28. Van Nooten GJ, Van Belleghem Y, Caes F, François K, Van Overbeke H, Bové T, et al. Lower-intensity anticoagulation for mechanical heart valves: a new concept with the ATS bileaflet valve. J Heart Valve Dis. 2003;12:495-501.
29. Puskas J, Gerdisch M, Nichols D, Quinn R, Anderson C, Rhenman B, et al. Reduced anticoagulation after mechanical aortic valve replacement: interim results from the prospective randomized on-x valve anticoagulation clinical trial randomized food and drug administration investigational device exemption trial. J Thorac Cardiovasc Surg. 2014;147: 1202-10.

Key Words: aortic valve, mechanical valve prosthesis, mitral valve, St Jude Medical, valve replacement

Readers who found these articles interesting may also like to read the following papers found in recent and future issues of our sister publications, Seminars in Thoracic and Cardiovascular Surgery and Operative Techniques in Thoracic and Cardiovascular Surgery!

\section{Adult: Aortic Valve}

ORIGINAL SUBMISSION: Single Dose Del Nido Cardioplegia in Minimally Invasive Aortic Valve Surgery. Daniel Ziazadeh. Semin Thoracic Surg 2017: 471-476

Editorial Commentary: Is "As Good" Good Enough? James I. Fann. Semin Thoracic Surg 2017: 477-478

ORIGINAL SUBMISSION: Aortic Root Reconstruction and Valve Repair During Acute Type A Aortic Dissection Repair. Jared P. Beller. Oper Tech Thorac Cardiovasc 2017: 80-90

ORIGINAL SUBMISSION: Repair of the Bicuspid Aortic Valve. Ulrich Schneider. Oper Tech Thorac Cardiovasc 2017: 91-109 